https://doi.org/10.18800/iusetveritas.201703.003 (c) (i)

\title{
Los niños y las niñas en la guerra: Respuestas desde el Derecho Internacional frente a los Crímenes de reclutamiento de niñas y niños soldados y violencia sexual ${ }^{(*)}$
}

\section{Children in war: Answers from International Law to the crimes of recruitment of child soldiers and sexual violence}

\author{
Valeria Reyes Menéndez ${ }^{(*)}$ \\ Pontificia Universidad Católica del Perú
}

\begin{abstract}
Resumen: A nivel mundial, los conflictos armados de los últimos años se han caracterizado por incluir la participación de niñas y niños soldados. Estos, por la vulnerabilidad propia de su corta de edad, sufren de manera diferenciada de los efectos de la guerra y ven afectados sus derechos humanos, algunas veces de manera irreversible. El Derecho Internacional tiene el deber de brindar respuestas a esta situación, velando en todo momento porque niños y niñas puedan ser protegidos frente a tales riesgos y que sus derechos puedan ser garantizados.
\end{abstract}

Palabras clave: Niños soldados - Derecho Internacional Humanitario - Derecho Penal Internacional - Crímenes de guerra - Violencia sexual Corte Penal Internacional

\begin{abstract}
Around the world, the armed conflicts of recent years have been characterized by including the participation of child soldiers. Children, due to the vulnerability of their short age, suffer in a special manner of the war effects, and often their human rights are violated irreversibly. International Law has a duty to provide effective answers to tackle this situation, ensuring that children can be protected against those risks and that their rights can be guaranteed.
\end{abstract}

(*) Nota del editor: Este artículo fue recibido el 25 de octubre de 2017 y su publicación fue aprobada el 16 de noviembre de 2017.

${ }^{* *}$ Abogada por la Pontificia Universidad Católica del Perú. Investigadora y Asistente Académica en el Instituto de Democracia y Derechos Humanos de la Pontificia Universidad Católica del Perú (IDEHPUCP). Miembro extraordinario de la Asociación IUS ET VERITAS. Correo electrónico: vreyes@pucp.pe 
Los niños y las niñas en la guerra: Respuestas desde el Derecho Internacional frente a los crímenes de reclutamiento de niñas y niños soldados y violencia sexual Children in war: Answers from International Law to the crimes of recruitment of child soldiers and sexual violence

Key words: Child soldiers - International Humanitarian Law - International Criminal Law - War crimes - Sexual Violence International Criminal Court

Sumario: 1. Introducción_2. Respuestas desde el Derecho Internacional frente a la participación de niños niñas soldados_2.1. Regulación en el Derecho Internacional Humanitario (DIH)_2.2. Regulación en el Derecho Internacional de los Derechos Humanos (DIDH)_ 2.3 Regulación en el Derecho Penal Internacional (DPI)_ 3. Respuestas desde el Derecho Internacional frente a la violencia sexual contra niñas y niños soldados_3.1 Regulación en el Derecho Internacional Humanitario (DIH)_3.2 Regulación en el Derecho Internacional de los Derechos Humanos (DIDH) 3.3 Regulación en el Derecho Penal Internacional (DPI)_ 3.3.1 La Corte Penal Internacional y el caso de Bosco Ntaganda_4. Conclusiones_5. Referencias bibliográficas.

\section{Introducción}

El reclutamiento y alistamiento de niños y niñas para integrar las filas de las fuerzas armadas de un Estado o de grupos armados organizados y participar así de los enfrentamientos que entre estos puedan desatarse, es una dura realidad de larga data que se ha intensificado particularmente durante la época contemporánea.

Este fenómeno tiene antiguos antecedentes en el tiempo. Por ejemplo, en 1864 con ocasión de la Batalla de New Market en el marco de la guerra civil americana, los cadetes menores de edad del Virginia Millitary Institute formaron parte de los enfrentamientos ${ }^{(1)}$. Por su parte, en 1945, cientos de jóvenes que conformaban el Hitler Jugend tuvieron un papel importante en la Batalla de Berlín entre la Alemana Nazi y la Unión Soviética (Trueman 2015). Asimismo, durante la Guerra Fría algunos grupos rebeldes incluyeron a niños dentro de sus listas (Singer 2010, 156). No obstante, hasta finales del siglo $X X$, estos hechos se presentaron como sucesos aislados en la historia, de modo que la participación de niños y niñas en la guerra podía considerarse como una excepción antes que una práctica generalizada (Singer 2010, 156).
Sin embargo, como mencionamos, la llegada del siglo XXI ha traído consigo un escenario desalentador en lo que respecta a la protección de los derechos humanos de niños y niñas. Al día de hoy más de 60 países se han visto afectados por conflictos armados internacionales y no internacionales, de una naturaleza compleja y en constante evolución, lo que plantea, sin duda, problemas para proteger a los niños y las niñas (Secretario General de las Naciones Unidas 2017, 3).

De este modo, actualmente en 18 países del mundo, aproximadamente 300 mil niños y niñas desde los nueve años de edad (Secretario General de las Naciones Unidas 2017) son reclutados o alistados por fuerzas armadas estatales y otros grupos armados organizados, viéndose obligados a participar no solamente en los enfrentamientos propios del conflicto, sino también como mensajeros, vigilantes, cocineros (Yuvaraj 2016, 69), esclavos sexuales, esposas de los miembros de las fuerzas armadas u otros grupos (Grey 2014, 601) entre otros.

Dando una mirada global, es posible observar que, en América, Asia, Medio Oriente y África, niños y niñas han sido víctimas de reclutamientos para participar en la guerra. En América, resalta el caso de Colombia, en donde a pesar de no existir cifras oficiales, se estima que las Fuerzas Armadas Revolucionarias de Colombia - Ejército del Pueblo (FARC - EP), el Ejército de Liberación Nacional (ELN) y los grupos armados no estatales surgidos tras la desmovilización del grupo paramilitar Autodefensas Unidas de Colombia (AUC) habían reclutado hasta el año 2012 entre 5 mil y 14 mil niños y niñas (Watch List on Children and Armed Conflict 2012, 14) ${ }^{(2)}$.

(1) Civil War Children, "The boys of war: Child Soldiers in the Civil War". https://civilwarchildren.wordpress.com/during-the-war-2/ john-sergeant-wise/1862-2/ (consultado el 23 de noviembre de 2017).

(2) Al respecto, cabe destacar que, según el Informe del Secretario General para las Naciones Unidas del 24 de agosto de 2017 , denominado "Los niños y los conflictos armados", el Acuerdo de Paz suscrito entre el Gobierno y las FARC-EP incluye una disposición referida a los intereses de los niños, niñas y adolescentes y la primacía de sus derechos en todas las esferas 


\section{Valeria Reyes Menéndez}

En el Medio Oriente y Asia, niños y niñas aún son víctimas de reclutamiento o alistamiento en países como Afganistán, Líbano, Siria, Libia, Sudán, Yemen, Filipinas, India, Myanmar y Pakistán. Destaca el caso de Afganistán, país en el que entre el 2015 y 2016, los casos de reclutamiento y utilización de niños y niñas en el conflicto se duplicaron. De igual manera, Siria, Estado que se encuentra al borde del colapso por la guerra civil que enfrenta desde el 2011, ha visto multiplicado por más de dos el número de niños y niñas reclutados entre el 2015 y 2016, llegando a la verificación de 851 casos. Asimismo, el caso de Pakistán, en donde niños y niñas han sido reclutados por grupos terroristas para participar en ataques suicidas, es también destacable (Secretario General de las Naciones Unidas 2017).

Finalmente, el fenómeno de reclutamiento de menores de edad en África reviste una particular gravedad, siendo este el continente que alberga de manera aproximada al $40 \%$ de niñas y niños reclutados a nivel global (Dudenhoefer 2016) ${ }^{(3)}$, un tercio del total de niños soldados, de conformidad con lo calculado por UNICEF hasta el año $2012^{(4)}$. De este modo, en países como Chad, Libia, Mali, República Centroafricana, República Democrática del Congo, Somalia, Nigeria y Sudán del Sur, el reclutamiento y alistamiento de menores de edad alcanza cifras preocupantes.

En la República Democrática del Congo, uno de los países más pobres a nivel mundial (ACNUR 2017; Ortiz y Cummins 2012 , 11) existen alrededor de 30 mil niñas y niños soldados; en otras palabras, aproximadamente uno de cada diez niñas y niños soldados del mundo se encuentra en este país. El reclutamiento de menores congoleses tiene por responsables tanto a fuerzas armadas del Estado, como a otros grupos rebeldes organizados. Por ejemplo, con respecto al primer grupo, de conformidad con lo señalado por SOS Children's Villages, ${ }^{(5)}$ entre el $15 \%$ y el $30 \%$ de los nuevos reclutados por las fuerzas armadas del Congo son niños y niñas.
El Secretario General de las Naciones Unidas ha enfatizado también los casos de la República Centroafricana, en dónde hacia el 2016, el número de menores reclutados con relación al año anterior aumentó prácticamente en un $50 \%$, afectando a niños y niñas de hasta nueve años de edad. Por otro lado, resaltó el caso de Nigeria en el que los 278 casos de reclutamiento del año 2015, aumentaron a 2122 en el año 2016; cobrando mayor protagonismo también las violaciones del grupo Boko Haram vinculadas en gran medida a actos de violencia sexual en contra de niñas (Secretario General de las Naciones Unidas 2017).

Ni siquiera el Perú ha sido ajeno a esta situación. De conformidad con el Informe Final de la Comisión de la Verdad y Reconciliación (CVR), de los actos de violencia dirigidos contra niños y niñas por parte de Sendero Luminoso, el reclutamiento forzado y el alistamiento bajo engaño o coacción, en las zonas más pobres del Perú, representó el $42,5 \%$. De esta manera, desde la década de 1980, Sendero Luminoso creó la organización niños pioneros o niños rojos incorporando en sus filas a menores desde los 11 años de edad a fin de que participen directamente en los enfrentamientos o realicen labores de vigilancia, mensajería, etc. (CVR 2003, 612-615). Incluso durante el año 2009, fue acreditado ante la prensa televisiva que los remanentes de Sendero Luminoso en la zona del valle de los ríos Apurímac, Ene y Mantaro (VRAE) continuaban reclutando a menores de edad (Save the Children 2010, 12). Esta

de implementación del acuerdo; motivo por el cual es posible tener una visión optimista sobre el futuro de los derechos de los niños y niñas en la etapa post conflicto a la que Colombia se encuentra próxima a ingresar.

(3) Anne - Lynn Dudenhoefer, "Understanding the Recruitment of Child Soldiers in Africa", African Centre for the Constructive Resolution of Disputes (ACCORD), http://www.accord.org.za/conflict-trends/understanding-recruitment-child-soldiers-africa/ (consultado el 23 de noviembre de 2017.

(4) Centro de noticias de la ONU, "UNICEF calcula hasta 300.000 niños soldados en el mundo", http://www.un.org/spanish/ News/story.asp?NewsID=22697\#.UYInYbV95qU (consultado el 23 de octubre de 2017).

(5) SOS Children's Villages, "Child Soldiers in DRC", http://www.child-soldier.org/child-soldiers-in-drc. 
Los niños y las niñas en la guerra: Respuestas desde el Derecho Internacional frente a los crímenes de reclutamiento de niñas y niños soldados y violencia sexual Children in war: Answers from International Law to the crimes of recruitment of child soldiers and sexual violence

misma práctica ha sido realizada por las fuerzas armadas del Estado peruano, desde la época del conflicto armado (CVR 2003, 602), hasta, por lo menos, el año 2009 (Save the Children 2010, 13).

El Derecho Internacional a través de sus diferentes ramas, plantea regulaciones orientadas no solo a proteger a niños y niñas frente al riesgo que supone que, a su corta edad, participen directa o indirectamente de un conflicto armado, imponiendo para ello determinadas obligaciones a los Estados; sino que también busca identificar a los y las responsables de esta exposición, de manera que su conducta criminal reciba una eventual sanción por parte de la justicia. Así pues, tanto el Derecho Internacional de los Derechos Humanos (en adelante, "DIDH"), como el Derecho Internacional Humanitario (en adelante, "DIH") y el Derecho Penal Internacional (en adelante, "DPI"), cuentan con disposiciones específicas para abordar los supuestos que venimos describiendo.

Sin embargo, existen diversos elementos y realidades en este fenómeno que todavía deben ser aclarados a efectos de brindar desde las instituciones del Derecho Internacional una protección más garantista a los derechos de niños y niñas, pues es claro que la prohibición sobre el reclutamiento de menores no será efectiva si sus conceptos básicos son poco claros o contradictorios (Mc Bride 2014, 61 en Yuvaraj 2016, 84). La tarea anterior implica a su vez, reconocer que las niñas sufren un impacto diferenciado por razón de género cuando son reclutadas pues además de participar en las hostilidades, son usualmente violadas, sexualmente esclavizadas y utilizadas como esposas por sus comandantes o compañeros de filas (Grey 2014, 601).

Todo ello plantea retos y exige respuestas eficientes al Derecho Internacional. En los próximos apartados veremos cuál es la regulación actual de estos crímenes y cómo han sido abordados por la jurisprudencia de la Corte Penal Internacional en los casos de Thomas Lubanga y Bosco Ntaganda. Asimismo, serán planteados algunos apuntes críticos sobre los puntos mencionados.

\section{Respuestas desde el Derecho Internacional frente a la participación de niños niñas soldados}

EI Derecho Internacional ha recogido a través del DIDH, el DIH y el DPI importantes disposiciones que, en función a la naturaleza de cada una de estas ramas, buscan dar una respuesta global a un fenómeno complejo, como es el del reclutamiento y alistamiento de niños y niñas para su participación en los conflictos armados, así como los delitos de violencia sexual que suelen cometerse en el marco de dicho reclutamiento. En este primer apartado, presentaremos de modo general las aproximaciones realizadas por cada una de estas disciplinas frente al reclutamiento y alistamiento de menores. Los crímenes de violencia sexual serán abordados posteriormente.

\subsection{Regulación en el Derecho Internacional Humanitario (DIH)}

El DIH es el conjunto de normas, de origen convencional o consuetudinario cuya finalidad específica es solucionar los problemas de índole humanitaria directamente derivados de los conflictos armados y que, por razones humanitarias, restringe la utilización de ciertos métodos o medios de combate (Salmón $2014,17)$. Aun cuando no existe una fórmula matemática para determinar el momento exacto en que el DIH empieza a aplicarse (Grignon 2015, 147), la doctrina reconoce que esta rama del Derecho será aplicable siempre que exista un conflicto armado, sea de carácter internacional o no internacional (Sassòli, Bouvier y Quintin 2011, 121). De igual modo, la mayor parte de las disposiciones del DIH se seguirán aplicando hasta que el conflicto alcance su fin, mientras que algunas otras partes sustanciales se mantendrán vigentes incluso luego del conflicto (Milanovic 2015, 188).

EI DIH está conformado, entre otras normas, por los cuatro Convenios de Ginebra de 1949 y los Protocolos Adicionales a dichos Convenios, de 1977. EI DIH busca otorgar una protección especial a los niños en tanto los considera personas particularmente vulnerables (Villasante 2011, 217). Precisamente, los Protocolos Adicionales han sido las primeras 


\section{Valeria Reyes Menéndez}

normas del DIH en reconocer de manera específica la prohibición de reclutar o alistar a niños y niñas para su participación en los conflictos armados. De esta manera, el numeral 2 del artículo 77 del Protocolo Adicional I (en adelante, "PA I"), aplicable a conflictos armados internacionales, establece que:

"Las Partes en conflicto tomarán todas las medidas posibles para que los niños menores de quince años no participen directamente en las hostilidades, especialmente absteniéndose de reclutarlos para sus fuerzas armadas. Al reclutar personas de más de quince años, pero menores de dieciocho años, las Partes en conflicto procurarán alistar en primer lugar a los de más edad." (La cursiva es de la autora).

Por su parte, el literal c) del numeral 3 del artículo 4 del Protocolo Adicional II (en adelante, "PA II"), aplicable a conflictos armados no internacionales, señala que:

"Se proporcionará a los niños los cuidados y la ayuda que necesiten y, en particular:

c) Los niños menores de quince años no serán reclutados en las fuerzas o grupos armados y no se permitirá que participen en las hostilidades." (La cursiva es de la autora)

Como se puede apreciar, el estándar de protección en cada uno de los protocolos es distinto pues, mientras que el PA I prohíbe solo la participación directa en las hostilidades, por parte de niños y niñas, el PA II proscribe cualquier tipo de participación, sea esta directa o indirecta. No obstante, el grado de diferencia en la protección que cada uno de dichos tratados regula, no es claro, debido a la falta de certeza sobre las actividades que podrían ser consideradas como participación directa en los términos del PA I (Yuvaraj 2016, 75). Para autores como Schabas esta sería una inconsistencia en la redacción, antes que una discusión jurídica real (Schabas 2010, 252 en Yuvaraj 2016, 75); sin embargo, existen algunas cuestiones prácticas que merecen ser anotadas.
En el DIH, el concepto de participación directa en las hostilidades, ha sido interpretado en función al principio de distinción ${ }^{(6)}$, en virtud del cual solamente aquellos que participan en las hostilidades y los objetivos militares debidamente identificados, podrán ser objeto de ataques, de modo que queda prohibido a la luz del DIH atacar a la población civil (Salmón 2014, 57), los miembros de las fuerzas armadas que hayan depuesto las armas y las personas puestas fuera de combate por enfermedad, herida, detención o por cualquier otra causa.

Frente a ello, el Comité Internacional de la Cruz Roja (en adelante, "CICR") elaboró en el año 2009, una guía para interpretar la noción de participación directa en las hostilidades según el DIH, la cual, si bien no es jurídicamente vinculante, propone importantes criterios que una determinada conducta debe alcanzar, para ser considerada como una participación directa en las hostilidades:

a) Umbral de daño; el acto debe tener probabilidades de afectar negativamente las operaciones o capacidad militar de una de las partes en conflicto, o de causar la muerte, heridas o destrucción de personas u objetos protegidos contra ataques directos.

b) Causalidad directa; debe existir una relación causal directa entre el acto perpetrado y el daño que este, o una operación militar de la cual él forma parte, genera.

c) Nexo Beligerante; el acto debe tener por finalidad causar el umbral de daño

(6) El principio de distinción se encuentra regulado en el artículo 3 común de los Convenios de Ginebra en los artículos 48 y 51 del PA I, y los artículos 4, 13.2 y 14 del PA II, así como las normas consuetudinarias No. 1, 6 y 7, compiladas por Jean Marie Henckaerts y Louis Doswald-beck, El derecho internacional humanitario consuetudinario, vol. I (Buenos Aires: Comité Internacional de la Cruz Roja, 2007). 
Los niños y las niñas en la guerra: Respuestas desde el Derecho Internacional frente a los crímenes de reclutamiento de niñas y niños soldados y violencia sexual Children in war: Answers from International Law to the crimes of recruitment of child soldiers and sexual violence

requerido en apoyo de una de las partes en conflicto y en desventaja de la otra (Melzer 2009).

Tomando ello en cuenta, discrepamos con Schabas cuando afirma que la diferencia en la redacción del PA I y el PA II refleja únicamente un problema de redacción, pues si la conclusión de esa afirmación es que ambos tratados se refieren al mismo estándar de protección, sería posible concluir también que cuando un menor participa de manera indirecta en las hostilidades, podría perder la protección que le otorga el principio de distinción, tal como sucede cuando participa de forma directa, según lo establecido por la Guía del CICR del año 2009.

La Corte Suprema de Israel emitió una sentencia en el año 2005 (HCJ 769/02), en el caso conocido como los targeted killings en el que tuvo que analizar qué conductas podían dar lugar a una participación directa en las hostilidades que despojara a los civiles de la protección garantizada por el principio de distinción. En el párrafo 35 de la sentencia, la Corte Suprema señala que actividades como recolectar información de inteligencia para las fuerzas armadas; transportar combatientes ilegales desde o hacia el lugar donde las hostilidades se han desatado; operar las armas de los combatientes ilegales o supervisar su uso; calzarían en dicha noción. En el mismo párrafo, la sentencia indica que actividades como vender comida o medicina a combatientes ilegales o financiarlos económicamente, no pueden ser consideradas como una participación directa en las hostilidades.

En definitiva, se trata de una regulación que no es clara ni conclusiva y que deberá ser dotada de contenido a través de la jurisprudencia. Pese a ello, coincidimos con los Comentarios al PA I propuestos por el CICR en el que, abordando la interrogante de si en tanto el artículo 77.2 prohíbe únicamente la participación directa de niños y niñas en las hostilidades, la participación indirecta sí sería legal. Al respecto, los Comentarios indican que claramente la intención de los redactores de este artículo era dejar a los menores fuera de los conflictos armados y que, en tal sentido, no debería interpretarse que el artículo bajo comentario faculta a los Estados a involucrar a niños y niñas en conductas que signifiquen su participación indirecta en las hostilidades, tales como transmitir información militar, transportar armas y municiones, etc.

\subsection{Regulación en el Derecho Internacional de los Derechos Humanos (DIDH)}

EI DIDH ha sido definido como aquella rama del Derecho Internacional cuyo objeto es el fomento del respeto a los derechos humanos y libertades fundamentales universalmente reconocidos, así como el establecimiento de mecanismos para la garantía y protección de tales derechos y libertades, los cuales se califican de preocupación legítima y, en algunos casos, de intereses fundamentales para la actual comunidad internacional de Estados en su conjunto (Villán 2002, 85-86 en Salmón 2006, 154).

En ese sentido, el DIDH está conformado en su gran mayoría por diversos tratados de derechos humanos que imponen obligaciones a los Estados de respeto y garantía de los derechos humanos, entendida esta última obligación, como el deber de prevenir, investigar y sancionar eventuales violaciones a tales derechos, así como procurar el restablecimiento del derecho vulnerado, y la reparación de los daños ocasionados (Salmón y Blanco 2012, 16).

En 1989, la Asamblea General de las Naciones Unidas, adoptó la Convención sobre los Derechos del Niño (en adelante, "CDN") (7), la cual entró en vigor el 02 de setiembre de 1990. Esta Convención señala en su artículo 1 que se entiende por niño a todo ser humano menor de 18 años de edad. Sin embargo, el numeral 2 del artículo 38 se pronuncia sobre el supuesto del reclutamiento y alistamiento de niños y niñas en conflictos armados e indica que:

"Los Estados Partes adoptarán todas las medidas posibles para asegurar que las personas que aún no hayan cumplido los 15 años de edad no participen directamente en las hostilidades" (Énfasis agregado).

(7) A la fecha, la Convención sobre los Derechos del Niño cuenta con 196 Estados Partes. 


\section{Valeria Reyes Menéndez}

Tal como indicamos con relación a la regulación del DIH para estos casos, la inclusión del término participación directa es desafortunada, pues deja abierta la posibilidad de que niños y niñas sean involucrados en conflictos armados para realizar conductas que signifiquen su participación indirecta en las hostilidades. Esto llama más la atención todavía, si se toma en cuenta que el documento que venimos analizando es un tratado de derechos humanos y que, en atención a dicha naturaleza, lo que buscaría es fomentar y promocionar el respeto por los derechos humanos, imponiendo a los Estados obligaciones que responden a altos estándares.

En ese sentido, consideramos que la mejor alternativa debió ser regular la obligación de los Estados Partes de tomar todas las medidas a su alcance para que niños y niñas no se vean expuestos a los riesgos propios de los conflictos armados, dejando fuera de su redacción el término participación directa y refiriéndose de manera general a cualquier tipo de participación en las hostilidades ${ }^{(8)}$.

La redacción actual de la CDN, se encuentra en armonía con la protección que ofrece el PA I del DIH en los casos de conflictos armados internacionales. No obstante, cuando de conflictos armados no internacionales se trata, tenemos que la CDN, un tratado de derechos humanos destinado a ser altamente garantista, termina ofreciendo una protección menor a niños y niñas, que la reconocida por el PA II, una norma de DIH que, en lugar de promover los derechos humanos, buscar preservar al ser humano para que este no se vea gravemente afectado como consecuencia de las hostilidades.

Cabe destacar que, en el año 2000, la Asamblea General de Naciones Unidas adoptó el Protocolo Facultativo de la Convención sobre los Derechos del Niño relativo a la participación de niños en los conflictos armados, el cual entró en vigor el 12 de febrero de $2002^{(9)}$. Este tratado, eleva la edad mínima para el reclutamiento de niños y niñas, señalando en su artículo 1 que "Los Estados Partes adoptarán todas las medidas posibles para que ningún miembro de sus fuerzas armadas menor de 18 años participe directamente en hostilidades". Introducida dicha modificación, se impone a los Estados una obligación mucho más exigente que la reconocida por la CDN.

Basándose en estos avances, la Corte Interamericana de Derechos Humanos, tribunal encargado de velar por el respeto y cumplimiento de la Convención Americana sobre Derechos Humanos, ha reconocido en su jurisprudencia la existencia de una tendencia en el Derecho Internacional a evitar que se incorpore a personas menores de 18 años en las fuerzas armadas de un Estado y a asegurar, que, en todo caso, los menores de 18 años no participarán directamente en las hostilidades ${ }^{(10)}$.

Sin embargo, la entrada en vigor del Protocolo Facultativo no solo trajo consigo progresos, sino que, por el contrario, dejó pasar una importante oportunidad para corregir la redacción de la CDN en lo que respecta a la participación directa de niños

(8) Cabe destacar que, de conformidad con los trabajos preparatorios para la redacción de la Convención sobre los Derechos del Niño, varios Estados hicieron notar que incluir el término directa referido al tipo de participación en las hostilidades que se buscaba prohibir, suponía reconocer una protección por debajo de los estándares vigentes en esta materia, refiriéndose claramente a la regulación del Protocolo Adicional II a los Convenios de Ginebra, el cual establece una prohibición absoluta del involucramiento de niños y niñas en los conflictos armados. Comité de Derechos Humanos. $45^{\circ}$ Sesión. Informe del Grupo de Trabajo sobre el Proyecto de Convención sobre los Derechos del Niño, presentado por el Dr. Adam Lopatka. 2 de marzo de 1989

(9) A la fecha, el Protocolo Facultativo de la Convención sobre los Derechos del Niño relativo a la participación de niños en los conflictos armados cuenta con 167 Estados Partes.

(10) Corte IDH. Caso Vargas Areco vs. Paraguay. Fondo, Reparaciones y Costas. Sentencia de 26 de septiembre de 2006 . Serie C No. 155. Párrafo 122 
Los niños y las niñas en la guerra: Respuestas desde el Derecho Internacional frente a los crímenes de reclutamiento de niñas y niños soldados y violencia sexual Children in war: Answers from International Law to the crimes of recruitment of child soldiers and sexual violence

y niñas en las hostilidades. Esto se debe a que dicho Protocolo nuevamente apunta a prohibir únicamente la participación directa de niños y niñas en las hostilidades, en lugar de apostar por una redacción que busque prohibir cualquier tipo de interacción de niños y niñas con los conflictos armados, ya sea directa o indirecta.

\subsection{Regulación en el Derecho Penal Internacional (DPI)} EI DPI ha sido definido como el conjunto de normas que regula aquellas conductas criminales que atentan contra los principales intereses de la comunidad internacional, y que se encuentran reguladas en diversos instrumentos internacionales o derivan del propio Derecho Internacional Consuetudinario (Barboza 1999, 24-25 citado por Reyes $2009,103)$. A diferencia del DIDH que permite establecer la responsabilidad internacional de los Estados por vulnerar sus obligaciones en materia de derechos humanos, el DPI, como parte del fenómeno de humanización, apunta a identificar la responsabilidad penal individual de aquellas personas que afectan los derechos humanos a través de la comisión de crímenes internacionales, entendidos estos como aquellas graves violaciones del Derecho que afectan los intereses legales de toda la humanidad (Bernhardt 2003, 1119-1123 citado por Reyes 2009, 112).

El reclutamiento de niños y niñas para participar de forma activa en las hostilidades es un crimen internacional. Así lo ha establecido el Estatuto de Roma, tratado que crea la Corte Penal Internacional y cuya entrada en vigor se remonta a julio de 2002. El numeral XXVI del literal b del numeral 2 del artículo 8 de dicho tratado, referido a los crímenes de guerra que pueden ser cometidos en el marco de un conflicto armado internacional, señala:

"2. A los efectos del presente Estatuto, se entiende por 'crímenes de guerra':

b) Otras violaciones graves de las leyes y usos aplicables en los conflictos armados internacionales dentro del marco establecido de derecho internacional, a saber, cualquiera de los siguientes actos:

xxvi) Reclutar o alistar a niños menores de 15 años en las fuerzas armadas nacionales o utilizarlos para participar activamente en las hostilidades." (La cursiva es de la autora).
Por su parte el numeral VII del literal e del mismo artículo, referido a los crímenes de guerra que pueden cometerse durante un conflicto armado no internacional, establece que:

"2. A los efectos del presente Estatuto, se entiende por 'crímenes de guerra':

e) Otras violaciones graves de las leyes y los usos aplicables en los conflictos armados que no sean de índole internacional, dentro del marco establecido de derecho internacional, a saber, cualquiera de los actos siguientes:

vii) Reclutar o alistar niños menores de 15 años en las fuerzas armadas o grupos o utilizarlos para participar activamente en las hostilidades" (La cursiva es de la autora).

Una de las principales consecuencias de esta regulación, implica que para que la comisión de este crimen pueda materializarse, debe existir un conflicto armado, ya sea de carácter internacional o no internacional. Si bien inicialmente se consideraba que los crímenes de guerra solo podían ser cometidos en el marco de un conflicto armado internacional, la propia jurisprudencia de los tribunales penales internacionales fue determinante para concluir que los crímenes de guerra podían tener también lugar durante un conflicto armado interno (Gutiérrez 2006, 10), lo cual, en el caso del reclutamiento o alistamiento de niñas y niños soldados, queda confirmado con la entrada en vigor del Estatuto de Roma.

En consecuencia, el reclutamiento, alistamiento o utilización de niños y niñas calificará como un crimen internacional a la luz del Estatuto de Roma siempre que se dé en el contexto del recurso a la fuerza armada entre dos o más Estados, conflicto armado internacional, o como parte de la violencia armada prolongada 


\section{Valeria Reyes Menéndez}

entre autoridades del gobierno y grupos armados organizados, o entre dichos grupos al interior de un Estado, conflicto armado no internacional ${ }^{(11)}$.

En ese sentido, el reclutamiento o alistamiento de niños y niñas no será considerado como un crimen internacional, si es realizado durante tiempos de paz. Nótese que ello no debe ser interpretado en el sentido de que una conducta como la descrita sea legítima o que deba ser admitida desconociendo la protección especial que los menores de edad merecen. Por el contrario, esta afirmación únicamente significa que tal comportamiento no dará lugar a un crimen de guerra en los términos propuestos por el Estatuto de Roma.

Por otro lado, la conducta típica del crimen consiste, tal como lo establece el Estatuto de Roma, en reclutar o alistar a niños menores de 15 años o utilizarlos para que participen activamente en las hostilidades. Como puede apreciarse, nos encontramos frente a tres conductas distintas y pasibles de sanción; a saber: (i) reclutar, (ii) alistar; o, (iii) utilizar a menores de 15 años para su participación activa en las hostilidades (Ambos 2012, 21).

Cabe mencionar que la redacción propuesta en el tipo penal del Estatuto, permite concluir que no es necesario que se presenten de manera concurrente las tres conductas para que el crimen internacional quede consumado. En efecto, la presencia de la conjunción o en la redacción sobre el delito, deja claro que la comisión de cualquiera de esas conductas es suficiente para la realización del ilícito (Ambos 2012, 21).

Ahora bien, en lo que se refiere al contenido de cada una de dichas conductas, es posible concluir que, mientras que la definición de "reclutar" supone la aplicación de un medio forzoso para la consecución del fin, la noción de "alistar" hace referencia, por su parte, a un elemento de voluntariedad en quien se une a las filas de las fuerzas armadas o de un grupo armado organizado (Ambos 2011, 21). Esto podría dar lugar a entender que es posible que los menores de 15 años de edad formen parte de fuerzas y grupos armados por voluntad propia, brindando para ello su consentimiento $y$, en consecuencia, no habría una conducta que sancionar.

Algunos supuestos de la realidad demuestran que en muchos casos, niños y niñas deciden de manera voluntaria integrarse a las fuerzas armadas de un Estado o a las filas de grupos armados organizados, lo que responde a causas tan variadas como el encontrarse inmersos en una situación familiar inadecuada, en contextos de pobreza o falta de educación, hasta la necesidad de cobrar venganza por la pérdida de un pariente cercano asesinado por fuerzas o grupos armados (Kirs 2006, 94), así como el supuesto enamoramiento o, simplemente, deseos de poder, tal como señala un estudio colombiano sobre la participación de niñas en las FARC-EP de Colombia (Moreno 2010, 453-457).

La decisión de un menor de 15 años de edad de integrarse a filas militares, sea para combatir en el marco de un conflicto armado o para cumplir labores accesorias, no puede ser considerada una decisión libre ni mucho menos voluntaria (Kirs 2006, 94). En consecuencia, resulta artificioso diferenciar si el niño o niña se incorporó a las filas de las fuerzas armadas o del grupo armado como parte de una conducta forzosa (reclutamiento) o una voluntaria (alistamento) ${ }^{(12)}$, sobre todo si se toma en cuenta que lo que la tipificación de estas conductas busca evitar es precisamente la exposición del menor a un contexto de altos riesgos para la vigencia de sus derechos humanos. En todo caso, comprendemos y estimamos que la intención del Comité de Redacción al proponer esta fórmula fue no dejar abierta la posibilidad de que pueda

(11) Decision on the Defence Motion for Interlocutory Appeal on Jurisdiction. Appeals Chamber Decision. Juicio de 2 de octubre de 1995, párrafo 70 .

(12) Tribunal Especial para Sierra Leona. Prosecutor vs. Moinina Fofana y Allieu Kondewa. Sentencia de primera instancia. 2 de agosto de 2007, párrafo 192. 


\section{Los niños y las niñas en la guerra: Respuestas desde el Derecho Internacional frente a los crímenes de reclutamiento de niñas y niños soldados y violencia sexual Children in war: Answers from International Law to the crimes of recruitment of child soldiers and sexual violence}

excluirse la responsabilidad penal de los perpetradores en el caso en que la incorporación del niño o niña soldado, haya sido de manera voluntaria.

Finalmente, el Estatuto de Roma sanciona también, al margen del reclutamiento o alistamiento de niños y niñas, su utilización para participar activamente en las hostilidades. El concepto de participación activa en las hostilidades, es novedoso en tanto su regulación se presenta por primera vez en el Estatuto de Roma y, en atención a ello, su contenido, aunque abordado eventualmente por la jurisprudencia (como veremos), es todavía poco claro.

La interpretación del enunciado citado exige remitirse de manera obligatoria al desarrollo planteado desde el DIH para la noción de la participación directa en las hostilidades. Ello, en primer lugar, debido a que el Estatuto de Roma considera a este delito como un crimen de guerra; es decir, una violación grave de una norma internacional de carácter convencional o consuetudinaria perteneciente al DIH (Gutiérrez 2006, 17). En ese sentido, resulta lógico que los tipos penales reconocidos en el Estatuto y que estén referidos a crímenes de guerra, deban ser interpretados a la luz de las disposiciones del DIH.

En segundo lugar, esta remisión se explica debido a que la tipificación del delito de reclutamiento o alistamiento de niñas y niños soldados en el Estatuto de Roma, es una apuesta por brindar consecuencias penales a las disposiciones recogidas tanto en el artículo 77.2 del PA I, como del artículo 4.3.c del PA II, artículos que, si bien prohíben la realización de las conductas mencionadas, no establecen sanciones para los responsables de llevarlas a cabo (Yuvaraj 2016, 77).

Al respecto, cabe precisar que, en torno al concepto de participación en las hostilidades, las palabras activa (en el artículo del Estatuto de Roma bajo análisis) y directa (en las normas del DIH como los Convenios de Ginebra y los Protocolos Adicionales) han sido entendidas en el Derecho Internacional como sinónimos ${ }^{(13)}$, concluyendo que se refieren a la misma calidad y grado de participación individual en las hostilidades (Melzer 2009, 43).

Esta afirmación, podría llevarnos a concluir que, en todo caso, lo que sanciona el Estatuto de Roma es la utilización de menores de edad para su participación directa en las hostilidades, según la propuesta del artículo 77.2 del PA I y del artículo 38.2 de la CDN. Así pues, el Estatuto ofrecería una protección menor a la reconocida por el artículo 4.3.c del PA II, en el entendido de que la conducta que prohíbe esa norma, es cualquier tipo de involucramiento de niños y/o niñas en los conflictos armados. Dicho de otra manera, el Estatuto de Roma optaría por no considerar un crimen de guerra, el utilizar a niños y niñas para la realización de labores que no cumplan con los requisitos de umbral de daño, causalidad directa y nexo beligerante (supra 2.1).

Una lectura del Estatuto, como la referida, ha sido ya descartada por la jurisprudencia de la Corte Penal Internacional para el caso de Thomas Lubanga, y también por la jurisprudencia del Tribunal Especial para Sierra Leona, al interpretar el literal c) del artículo 4 de su propio Estatuto ${ }^{(14)}$. En ambos casos se ha confirmado que la participación activa que contempla el delito de reclutamiento de menores, en tanto lo que se busca es proteger a los niños y las niñas de los peligros

(13) Tribunal Penal Internacional para Ruanda. Prosecutor vs. Jean Paul Akayesu. Fallo. 2 de setiembre de 1998, párrafo 629.

(14) El literal c del artículo 4 del Estatuto del Tribunal Especial para Sierra Leona, adopta una redacción idéntica a la propuesta en el artículo 8.2.e.VII del Estatuto de Roma, relativo a los conflictos armados no internacionales, tomando en consideración la naturaleza interna del conflicto que se desarrolló en Sierra Leona desde 1996:

"4. The Special Court shall have the power to prosecute persons who committed the following serious violations of international humanitarian law

$(\ldots)$

c) Conscripting or enlisting children under the age of 15 years into armed forces or groups or using them to participate actively in hostilities". 


\section{Valeria Reyes Menéndez}

de la guerra(15), está referida también a conductas que se relacionan con actividades o roles de apoyo ${ }^{(16)}$ y que podrían considerarse como de carácter accesorio. Como ejemplo de estas actividades, se encuentran aquellas vinculadas a la búsqueda de comida, municiones o armas, a la actuación de los niños soldados como señuelos o mensajeros ${ }^{(17)}$, como guardaespaldas de sus líderes ${ }^{(18)}$, o como espías, cocineros, porteros o sirvientes ${ }^{(19)}$.

Sobre este punto, vale también presentar las conclusiones a las que llega la Sala de Apelaciones de la Corte Penal Internacional en la sentencia para el caso Lubanga. El 14 de marzo de 2012, dicho Tribunal emitió su primer fallo desde la entrada en vigor del Estatuto de Roma, declarando culpable a Thomas Lubanga Dyilo por la comisión del crimen de guerra consistente en reclutar, alistar o utilizar niñas y niños soldados menores de 15 años para su participación activa en las hostilidades. El periodo analizado por la Corte se extendió desde julio de 2002 hasta diciembre de 2003, tiempo en el que se desarrolló el conflicto armado de Ituri, en la República Democrática del Congo.

Esta sentencia condenatoria fue apelada por la defensa de Lubanga. El principal argumento del apelante fue que la Sala de primera instancia habría interpretado de manera excesivamente amplia el concepto de participación activa en las hostilidades al valorar como un criterio de interpretación, el riesgo al que se enfrentaba un menor de edad cuando se involucraba en un conflicto armado, a pesar de que dicho criterio de interpretación no encontraba respaldo en el Derecho Internacional(20).

La conclusión de la defensa de Lubanga fue parcialmente aceptada por la Sala de Apelaciones, la cual consideró que el contenido del concepto de participación activa debía definirse en función a la relación entre las actividades que realizaba el niño o la niña reclutado y las hostilidades que tenían lugar. Sin embargo, la Sala aclaró que, mientras más alto era el riesgo para los intereses del menor reclutado, podía entenderse que existía una relación más directa o cercana entre las actividades realizadas por el niño o niña y las hostilidades, lo que debería llevar a identificar, en consecuencia, la presencia de una participación activa en las hostilidades ${ }^{(21)}$.

Asimismo, la Sala se remitió a los comentarios del CICR con respecto al artículo 4.3.c del PA II para presentar una lista ilustrativa de las conductas que significarían una participación activa en las hostilidades y que estarían prohibidas por el Estatuto de Roma ${ }^{(22)}$ refiriéndose, por ejemplo, al transporte de municiones, actos de sabotaje, recojo de información, entre otros ${ }^{(23)}$.

La línea de interpretación del concepto de participación activa hasta aquí presentada, ofrece una protección mayor a los niños y niñas que se ven involucrados en un conflicto armado realizando incluso actividades menores, pues permite imputar responsabilidad penal, con sus respectivas sanciones, a aquellos sujetos que, al exponerlos a los riesgos de un conflicto, atentan contra sus intereses. No obstante, la lectura propuesta, genera también, al menos

(15) Tribunal Especial para Sierra Leona. Sentencia. Prosecutor vs. Charles Ghankay Taylor. 18 de mayo de 2012. Párrafo 444.

(16) Tribunal Especial para Sierra Leona. Sentencia. Prosecutor vs. Brima, Kamara y Kanu, Trial. 20 de junio de 2007. Párrafo 737.

(17) Tribunal Especial para Sierra Leona. Sentencia. Prosecutor vs. Charles Ghankay Taylor. Ibídem.

(18) Tribunal Especial para Sierra Leona. Sentencia. Sentencia Prosecutor vs. Issa Hassan Sessay, Morris Kallon, Augustine Gbao. 8 de abril de 2009, párrafo 180.

(19) Eszter Kirs, "Save the children of War! Thoughts on child recruitment", http://publikacio.uni-miskolc.hu/data/ME-PUB-10101/ Kirs_save.pdf (consultado el 23 de noviembre de 2017.

(20) The Appeals Chamber. Judgement on the appeal of Mr. Thomas Lubanga Dyilo against his conviction. 01 de diciembre de 2014. Párrafo 319.

(21) Ibídem Párrafo 333.

(22) Ibídem Párrafo 334.

(23) CICR. Comentarios a los Protocolos Adicionales de junio de 1977 a las Convenciones de Ginebra de 1949, citado en el pie de página No. 616 de la Sentencia en apelación del caso Lubanga. 
Los niños y las niñas en la guerra: Respuestas desde el Derecho Internacional frente a los crímenes de reclutamiento de niñas y niños soldados y violencia sexual Children in war: Answers from International Law to the crimes of recruitment of child soldiers and sexual violence

en apariencia, una desventaja de cara a la protección que garantiza el DIH para la población civil, los miembros de las fuerzas armadas que hayan depuesto las armas y las personas puestas fuera de combate por enfermedad, herida, detención o por cualquier otra causa (Rodenhäuser 2016, 178).

Ello se debe a que realizar una lectura amplia del concepto de activa y afirmar que este es sinónimo de la noción de directa, nos debería llevar también a concluir que siempre que una persona protegida participe de manera activa / directa en las hostilidades, incluso a través de la realización de conductas accesorias o de apoyo, perdería la protección que le reconoce el principio de distinción del DIH. Lo anterior es sin duda un riesgo. En efecto, esta afirmación, reduce la protección que actualmente reconoce el DIH, pues permitiría, por ejemplo, que personas de la población civil que se encargan de la alimentación de las fuerzas armadas, puedan convertirse en objetivos militares válidos en el marco de un ataque.

No obstante, parte de la doctrina (a la que nos adherimos) propone una solución intermedia a este conflicto, entendiendo que elevar el estándar de protección para los niñas y niños soldados desde el DPI, no debe suponer necesariamente disminuir el estándar de protección para las personas protegidas por el DIH. La principal justificación para esta explicación se encontraría en que ambos conceptos están ubicados en cueros normativos diferentes, y también en que el propio artículo 10 del Estatuto de Roma ${ }^{(24)}$, indica que lo dispuesto en dicho tratado no debe ser interpretado en el sentido que limite o menoscabe otras normas del Derecho Internacional (Yuvaraj 2016, 79-80).

\section{Respuestas desde el Derecho Internacional frente a la violencia sexual contra niñas y niños soldados}

Como hemos ya mencionado, el fenómeno del reclutamiento de niñas y niños soldados, tiene un impacto diferenciado por razón de género en las niñas. En la mayoría de casos, las niñas reclutadas o alistadas no solo son utilizadas para participar activamente en las hostilidades cumpliendo roles con una mayor carga militar, como formar parte de las filas de ataque, o roles de carácter accesorio, como encargarse de la limpieza de las armadas del grupo, sino que se convierten también en víctimas de violencia sexual por parte de sus captores o de otros miembros de las fuerzas armadas o el grupo armado que integran.

Según lo ha señalado, Radhika Coomaraswamy, Representante Especial del Secretario General para la Cuestión de los Niños y los Conflictos Armados de Naciones Unidas entre el 2006 y el 2012, las niñas reclutadas o alistadas, desarrollan múltiples roles durante los conflictos armados, algunas veces vinculados directamente a los enfrentamientos, pero también son forzadas a convertirse en esclavas sexuales ${ }^{(25)}$.

En el 2012, la jueza Odio Benito emitió una opinión disidente a la sentencia de la Corte Penal Internacional en el caso de Lubanga, en la que destacó el impacto diferenciado que el reclutamiento tiene en niñas soldadas, respecto a los niños soldados, quienes son algunas veces relegados a cargos de guardaespaldas, mientras que las niñas son esclavizadas sexualmente(26). En dicho voto, la jueza Odio Benito presentó acertados ejemplos de las graves consecuencias que pueden alcanzar a las niñas reclutadas o alistadas en lo que respecta a su integridad sexual(27); sin embargo, falló al calificar a los

(24) Artículo 10: Nada de lo dispuesto en la presente parte se interpretará en el sentido de que limite o menoscabe de alguna manera las normas existentes o en desarrollo del derecho internacional para fines distintos del presente Estatuto.

(25) The Prosecutor vs. Thomas Lubanga Dyilo. Caso No. ICC-01/04-01/06 (La Haya: Corte Penal Internacional, 2010).

(26) Trial Chamber. Judgement pursuant to article 74 of the Statute. Separate and dissenting opinion of Judge Odio Benito. Párrafo 21

(27) Ibídem. Párrafo 20: "Girls who are used as sex slaves or "wives" of commanders or other members of the armed group provide essential support to the armed groups. Sexual assault in all its manifestations produces considerable damage and 


\section{Valeria Reyes Menéndez}

actos de violencia sexual que sufren estas víctimas como un elemento propio de la conducta típica referida a la utilización para su participación activa en las hostilidades.

La aproximación propuesta por la jueza Odio Benito, que será analizada en mayor detalle en líneas posteriores, trae como una de sus principales consecuencias la invisibilización de la violencia sexual que sufren las niñas soldadas, situación que merece por sí misma una respuesta específica desde el Derecho Internacional. A continuación, veremos cómo ha sido abordada la violencia sexual en contra de niñas, principalmente, y niños soldados ${ }^{(28)}$, desde el DIDH, el DIH y el DPI.

\subsection{Regulación en el Derecho Internacional Humanitario (DIH)}

El Cuarto Convenio de Ginebra de 1949, que se ocupa de la protección de civiles en el contexto de un conflicto armado internacional, señala en su artículo 27 que "(...) Las mujeres serán especialmente protegidas contra todo atentado a su honor y, en particular, contra la violación, la prostitución forzada y todo atentado a su pudor". De modo similar, el numeral 1 del artículo 76 de PA I, relativo a la protección de mujeres, indica que "[I]as mujeres serán objeto de un respeto especial y protegidas en particular contra la violación, la prostitución forzada y cualquier otra forma de atentado al pudor".

Por su parte, el literal e) del numeral 2 del artículo 4 del PA II, establece que están prohibidos "los atentados contra la dignidad personal, en especial los tratos humillantes y degradantes, la violación, la prostitución forzada y cualquier forma de atentado al pudor".

En esa medida, es cierto que el DIH prohíbe todos los actos de violencia sexual, aun cuando solo se refiera de manera expresa a algunos de ellos, como la violación o la prostitución forzada; pero, sobre todo, es cierto también que el DIH identifica que, en situaciones de conflicto armado, la mujer es particularmente vulnerable y, por tal motivo, le ofrece una protección especial a partir del contenido de sus disposiciones.

Ahora bien, no es menos cierto que el DIH no se ha ocupado específicamente del problema relativo a la violencia sexual cometida frecuentemente contra niñas soldadas. Como ya hemos visto, ambos Protocolos Adicionales a los Convenios de Ginebra, prohíben expresamente el reclutamiento de niños y niñas para su participación en las hostilidades; sin embargo, ninguna de estas normas menciona (aunque pueda parecer hasta innecesario) que esté prohibido cometer actos de violencia sexual en contra de las víctimas reclutadas.

Existen importantes indicios para considerar que la necesidad de incluir esta prohibición en dichos Protocolos, no estuvo en la mente de los redactores (Grey 2014, 606). Por ejemplo, los Comentarios a los Protocolos Adicionales, señalan que, como parte del principio de no reclutamiento, está prohibido que niños y niñas participen en las hostilidades, dedicándose a tareas como la obtención de información, la transmisión de órdenes, el transporte de municiones y víveres, o los actos de sabotaje. No obstante, nada se dice en los Comentarios con respecto a que también dicho principio prohíba que se realicen actos de violencia sexual en contra de niñas reclutadas o alistadas.

De igual manera, tanto en el PA I como en el PA II, las normas que prohíben la perpetración de violencia sexual, y aquellas

it demonstrates a failure in the protection of the life and integrity of its victim. There is additionally a gender-specific potential consequence of unwanted pregnancies for girls that often lead to maternal or infant's deaths, disease, HIV, psychological traumatisation and social isolation".

(28) Esta sección del artículo busca poner énfasis en el impacto diferencia que tiene el reclutamiento en las niñas soldadas, frente a los niños soldados, en relación con actos de violencia sexual. Ello no quiere decir que los niños soldados no sufran también de violencia sexual como parte de su reclutamiento, sino que las niñas son particularmente afectadas pues suelen ser víctimas de dichos delitos con mucha mayor frecuencia que los niños. 
Los niños y las niñas en la guerra: Respuestas desde el Derecho Internacional frente a los crímenes de reclutamiento de niñas y niños soldados y violencia sexual Children in war: Answers from International Law to the crimes of recruitment of child soldiers and sexual violence

que prohíben el reclutamiento de niños y niñas, se encuentran unas inmediatamente después de las otras; sin embargo, no dialogan en el sentido de aplicarse de manera concurrente a un mismo supuesto. Por el contrario, estas normas parecerían apuntar a situaciones distintas e independientes que buscan proteger cada cual por su lado a grupos vulnerables como lo son los niños, niñas y mujeres.

\subsection{Regulación en el Derecho Internacional de los Derechos Humanos (DIDH)}

EI DIDH presenta un panorama similar el DIH en cuanto a la protección que ofrece a las niñas reclutadas. Según ha sido indicado, la CDN y su Protocolo Facultativo relativo a la participación de niños en los conflictos armados, se ocupan del problema del reclutamiento y alistamiento de niñas y niños soldados, prohibiendo esta conducta en beneficio de todo menor de 18 años. No obstante, el silencio es rotundo cuando de violencia sexual en contra de niñas reclutadas o alistadas, se trata.

Al respecto, la CDN contiene dos artículos en relación con la protección la integridad sexual de los niños. El artículo 19.1 señala que los Estados Partes deben adoptar todas las medidas legislativas, administrativas, sociales y educativas apropiadas para proteger al niño, entre otras cosas, del abuso sexual. Por otro lado, el artículo 34 de la CDN recoge de manera general la prohibición de explotar sexualmente a los niños o abusar sexualmente de ellos ${ }^{(29)}$.

Cabe resaltar que, en este último caso, la prohibición mencionada parecería estar referida además a supuestos de trata o tráfico de niños y niñas, o casos de explotación sexual en un sentido comercial, antes que a situaciones de violencia sexual en el marco de su reclutamiento para participar en los conflictos armados. Ello se debe a que el artículo bajo comentario aborda de manera específica prácticas ilegales como la prostitución forzada o la utilización de niños y niñas en la pornografía, así como las obligaciones que deben emprender los Estados a nivel bilateral o multilateral, para frenar dichos crímenes.

En consecuencia, los tratados de derechos humanos que se refieren especialmente a la protección de los niños y niñas frente al riesgo de su reclutamiento o alistamiento militar, no garantizan ningún tipo de protección concreta a las niñas víctimas de violencia sexual como resultado de dicho reclutamiento.

\subsection{Regulación en el Derecho Penal Internacional (DPI)}

La aproximación del DPI a los crímenes sexuales y el desarrollo que ha realizado del contenido de estas conductas y su eventual sanción incluso en caso de la violencia sexual intra filas, viene siendo más alentador que los casos abordados en los dos apartados anteriores.

Tanto la jurisprudencia del Tribunal Penal Internacional para la Ex Yugoslavia(30) como la del Tribunal Penal Internacional para Ruanda(31), han sido clave para que los crímenes sexuales puedan visibilizarse en el Derecho Penal Internacional (Grey 2014, 604). En definitiva, esa visibilización alcanzó

(29) "Artículo 34:

Los Estados Partes se comprometen a proteger al niño contra todas las formas de explotación y abuso sexuales. Con este fin, los Estados Partes tomarán, en particular, todas las medidas de carácter nacional, bilateral y multilateral que sean necesarias para impedir:

a) La incitación o la coacción para que un niño se dedique a cualquier actividad sexual ilegal;

b) La explotación del niño en la prostitución u otras prácticas sexuales ilegales;

c) La explotación del niño en espectáculos o materiales pornográficos".

(30) Resalta dentro de la jurisprudencia del Tribunal Penal Internacional para la Ex Yugoslavia, el caso de Anto Furundzija, cuya sentencia condenatoria fue emitida por el Tribunal el 10 de diciembre de 1998.

(31) Resalta dentro de la jurisprudencia del Tribunal Penal Internacional para Ruanda, el caso de Jean Paul Akayesu, cuya sentencia condenatoria fue emitida por el Tribunal el 2 de setiembre de 1998 y confirmada en apelación el 01 de junio de 2001. 


\section{Valeria Reyes Menéndez}

su punto de consolidación con la entrada en vigor del Estatuto de Roma, tratado que recoge una lista importante de crímenes sexuales que pueden ser cometidos bajo las características de crímenes de guerra, crímenes de lesa humanidad o genocidio $^{(32)}$.

Aun cuando, al igual que en los otros casos ya presentados, el Estatuto de Roma no se refiere de forma expresa a la prohibición de cometer actos de violencia sexual en contra de niñas soldadas, desde la Corte Penal Internacional se han presentado otras iniciativas importantes que permiten brindar una respuesta a la situación que venimos discutiendo. Por ejemplo, en el 2014, la Fiscalía de la Corte presentó una Política sobre crímenes basados en sexo y género, en la que mencionó que los crímenes sexuales reconocidos en el Estatuto de Roma abarcaban también la violencia sexual en contra de niñas reclutadas o alistadas ${ }^{(33)}$.

Sin embargo, si podemos señalar un paso clave dado desde la Corte hacia la protección de niñas soldadas, ese sería la decisión de confirmación de cargos en contra del ex líder congolés Bosco Ntaganda del 09 de junio de 2014. En dicha decisión, la Sala de Cuestiones Preliminares confirmó que Ntaganda podía ser procesado por la comisión del crimen de guerra reconocido en el artículo 8.2.e.VI del Estatuto de Roma, referido a violencia sexual cometida contra niñas reclutadas para integrar las filas del grupo armado Union des Patriotes Congolais / Forces patriotiques pour la libération du Congo liderado por Lubanga y Ntaganda durante el conflicto armado en la República Democrática del Congo.

\subsubsection{La Corte Penal Internacional y el caso de Bosco Ntaganda}

Bosco Ntaganda fue Sub Jefe de Estado Mayor y Comandante de operaciones del grupo armado Union des Patriotes Congolais / Forces patriotiques pour la libération du Congo durante el conflicto armado no internacional que tuvo lugar en la provincia de Ituri, en la República Democrática del Congo entre el 2002 y el 2003.

El 22 de agosto de 2006, la Sala de Cuestiones Preliminares de la Corte Penal Internacional emitió una primera orden de arresto en contra de Ntaganda, por el crimen de guerra de reclutamiento de niñas y niños soldados, la cual fue hecha pública el 28 de abril de 2008. El 13 de julio de 2012, la Sala de Cuestiones Preliminares emitió una segunda orden de

(32) Estatuto de Roma:

"Artículo 6.- A los efectos del presente Estatuto, se entenderá por "genocidio" cualquiera de los actos mencionados a continuación, perpetrados con la intención de destruir total o parcialmente a un grupo nacional, étnico, racial o religioso como tal:

b) Lesión grave a la integridad física o mental de los miembros del grupo

d) Medidas destinadas a impedir nacimientos en el seno del grupo.

Artículo 7.-A los efectos del presente Estatuto, se entenderá por "crimen de lesa humanidad" cualquiera de los actos siguientes cuando se cometa como parte de un ataque generalizado o sistemático contra una población civil y con conocimiento de dicho ataque:

g) Violación, esclavitud sexual, prostitución forzada, embarazo forzado, esterilización forzada o cualquier otra forma de violencia sexual de gravedad comparable.

Artículo 8.2.- A los efectos del presente Estatuto, se entiende por "crímenes de guerra":

b) xxii) Cometer actos de violación, esclavitud sexual, prostitución forzada, embarazo forzado, definido en el apartado f) del párrafo 2 del artículo 7, esterilización forzada y cualquier otra forma de violencia sexual que también constituya una infracción grave de los Convenios de Ginebra.

e) Cometer actos de violación, esclavitud sexual, prostitución forzada, embarazo forzado, definido en el apartado f) del párrafo 2 del artículo 7 , esterilización forzada o cualquier otra forma de violencia sexual que constituya también una violación grave del artículo 3 común a los cuatro Convenios de Ginebra".

(33) Office of the Prosecutor, "Policy Paper on Sexual and Gender-Based Crimes," International Criminal Court, junio de 2014, p. 20, https://www.icc-cpi.int/iccdocs/otp/OTP-Policy-Paper-on-Sexual-and-Gender-Based-Crimes--June-2014.pdf. 
Los niños y las niñas en la guerra: Respuestas desde el Derecho Internacional frente a los crímenes de reclutamiento de niñas y niños soldados y violencia sexual Children in war: Answers from International Law to the crimes of recruitment of child soldiers and sexual violence

arresto contra Ntaganda, en la que se incluyeron cuatro cargos adicionales por crímenes de lesa humanidad y cinco nuevos cargos por crímenes de guerra, incluidos los crímenes sexuales de violación y esclavitud sexual. En marzo de 2013, Ntaganda se entregó a la jurisdicción de la Corte y es recién en esa oportunidad que la Fiscal, Fatou Bensouda, solicita que la Sala de Cuestiones Preliminares confirme en su contra cargos por el crimen de guerra de violencia sexual en contra de las niñas soldadas reclutadas en sus filas.

La solicitud de la Fiscal supuso una serie de retos sobre todo de cara al principio de legalidad reconocido en el artículo 22 del Estatuto de Roma ${ }^{(34)}$ y que fue prontamente alegado por la defensa del acusado, señalando que el DIH no prohíbe esta conducta y que, en consecuencia no podía haber un crimen de guerra, entendido como una grave infracción al DIH, ahí donde no hay una norma prohibitiva.

De igual manera, la defensa alegó que la violencia sexual intra filas no podía ser procesada al amparo del Estatuto de Roma sino del DIDH y el derecho interno congolés. Ello debido a que el DIH no pretende proteger a los combatientes de delitos cometidos por otros combatientes desde su mismo grupo, lo cual tendría respaldo incluso en el literal d del numeral 3 del artículo 4 del PA II que prevé una protección particular para niñas y niños soldados cuando son capturados por el enemigo.

Desde luego, considerar a este delito como un crimen de guerra era problemático porque este tipo de crímenes no solo exige una relación con el conflicto, sino que están aparentemente orientados a regular las conductas de los perpetradores hacia sus oponentes o la población civil, y no hacia los miembros de su mismo grupo. De cierta manera se ha asumido que las conductas ilícitas contra los propios compañeros, debían ser reguladas a través de otros canales, como la disciplina interna del grupo (Grey 2014, 605).

Pero la calificación propuesta era también problemática debido a que el artículo 8.2.e.vi que sanciona los crímenes sexuales en conflictos armados no internacionales, considera que estos representan violaciones al artículo 3 común a los Convenios de
Ginebra, el cual regula el principio de distinción y prohíbe atacar a la población civil.

En esa medida, un primer reto para la Fiscalía era llevar a la Sala de Cuestiones Preliminares a la convicción de que las niñas soldadas: (i) ostentan una protección especial desde el DIH frente a la violencia sexual, (ii) que esta protección se mantiene al margen de que pudieran participar activamente de las hostilidades, y (iii) que entender que esa protección es solo frente a sus adversarios era una interpretación muy limitada.

El argumento normativo presentado por Bensouda fue que las niñas soldadas tenían garantizadas las protecciones generales que están vigentes durante los conflictos armados no internacionales y que se encuentran reconocidas en el artículo 4 del PA II y el artículo 3 común a los Convenios de Ginebra. Adicionalmente, y como argumento más fuerte, la Fiscal señaló que estas niñas tenían una protección especial por causa de su vulnerabilidad como menores de edad, la cual se encontraba reconocida por el artículo 4.3 del PA II(35).

La Sala de Cuestiones Preliminares aceptó solo de manera parcial los argumentos presentados por la Fiscalía. Así, reconoció que las niñas soldadas sí tienen una protección especial al amparo de las normas del DIH, pero que dicha protección se pierde cuando participan activamente de las hostilidades. Sin embargo, la Sala encontró una salida que consideramos acertada (aunque lleve a ciertas inconsistencias) para afirmar que las niñas soldadas se encontraban protegidas frente actos de violencia sexual y que realizar dichos actos, en consecuencia, sí daba lugar

(34) "Artículo 22.- Nullum crimen sine lege:

b) La definición de crimen será interpretada estrictamente y no se hará extensiva por analogía. En caso de ambigüedad, será interpretada en favor de la persona objeto de investigación, enjuiciamiento o condena".

(35) The Prosecutor vs. Bosco Ntaganda. Caso No. ICC-01/04-02/06 (La Haya: Corte Penal Internacional, 2014). 


\section{Valeria Reyes Menéndez}

al crimen de guerra reconocido en el 8.2.e.vi del Estatuto de Roma. En términos de la Sala, las características que rodean a las violaciones sexuales y esclavitud sexual, cargos imputados a Ntaganda, impiden que en el mismo momento que tales actos se están llevando a cabo, la víctima se encuentre también participando activamente en las hostilidades. Un acto imposibilita al otro. En esa medida, las víctimas no perdían la protección del DIH mientras eran sexualmente, abusadas precisamente por no encontrarse participando activamente de las hostilidades.

Esta decisión fue apelada por la defensa de Ntaganda, bajo el argumento de que la interpretación realizada por la Sala de Cuestiones Preliminares era incorrecta y que la propia pertenencia de las niñas soldadas al grupo armado significaba que estas participaban de forma permanente de las hostilidades, pues, según señaló "el concepto de ser miembro de las fuerzas armadas es incompatible con la idea de no participar activamente de las hostilidades"(36). Esta apelación fue resuelta por la Sala de Apelaciones a través de su decisión del 15 de junio de 2017 respaldando las conclusiones a las que había llegado la Sala de Cuestiones Preliminares y, de esa manera, confirmando la competencia de la Corte Penal Internacional para seguir adelante con el proceso.

Consideramos que los pasos hasta aquí adoptados por la Corte Penal Internacional en el caso de Bosco Ntaganda son adecuados y permitirán brindar una respuesta contundente desde el DPI para la protección de las niñas soldadas frente a los riesgos de violencia sexual a los que se encuentran expuestas como parte de su reclutamiento. Otra alternativa a la que se pudo recurrir, aunque no fue discutida por la Fiscalía, fue imputar los cargos a Ntaganda bajo el esquema de crímenes sexuales en la modalidad de crímenes de lesa humanidad.

Esta fue, por ejemplo, la alternativa elegida en el caso de Charles Taylor resuelto por el Tribunal Especial para Sierra Leona. En ese caso, el Tribunal optó por imputar dos cargos distintos al ex presidente de Liberia, a saber, uno por el reclutamiento y alistamiento de niñas y niños soldados, y otro por la violencia sexual cometida contra las niñas reclutadas, como un crimen de lesa humanidad. Dicha apuesta fue deliberada y buscó presentar una fotografía completa del destino de los menores reclutados, especialmente, el de las niñas. (Jorgensen 2012, 659 citado por Grey 2014, 608).

Aun cuando pensamos que la violencia sexual intra filas del caso Ntaganda reuniría en principio los requisitos que exige el tipo penal de crímenes de lesa humanidad, realizar un análisis en ese sentido supera los fines del presente artículo. Nos encontramos frente a un caso que reconoce la doble afectación que sufren las niñas reclutadas, como niñas soldadas y como víctimas de violencia sexual. Por lo pronto, solo nos queda esperar con optimismo a una sentencia final que consolide lo hasta aquí alcanzado por la Corte Penal Internacional.

\section{Conclusiones}

El reclutamiento o alistamiento de niños y niñas menores de 15 años para su participación en las hostilidades es un fenómeno de carácter contemporáneo que en los últimos años ha afectado gravemente los derechos humanos de cientos de miles de niños y niñas alrededor del mundo. El Derecho Internacional, a través de sus ramas como el DIH, el DIDH, y DPI ha buscado plantear respuestas, pero sobre todo acciones, para frenar los perjudiciales resultados de estos crímenes. Sin embargo, aún existen muchas zonas grises en cuanto a cómo interpretar las normas que buscan ofrecer una protección integral a las víctimas y también una dura sanción a los responsables. Desde luego, la jurisprudencia de la Corte Penal Internacional para el caso

(36) The Prosecutor vs. Bosco Ntaganda. Judgement on the appeal of Mr. Ntaganda against the "Second decision on the Defence's challenge to the jurisdiction of the Court in respect of Counts 6 and 9". Caso No. ICC-01/04-02/06-1962 (La Haya: Corte Penal Internacional, 2017), párrafo 16. 
Los niños y las niñas en la guerra: Respuestas desde el Derecho Internacional frente a los crímenes de reclutamiento de niñas y niños soldados y violencia sexual Children in war: Answers from International Law to the crimes of recruitment of child soldiers and sexual violence

de Thomas Lubanga representó un hito importante en el objetivo de proteger a niños y niñas de los peligros de la guerra, pero queda todavía una enorme tarea pendiente hasta el momento en que el Derecho Internacional brinde una respuesta eficaz a esta situación.

Dentro del fenómeno descrito, además, las niñas, por cuestión de su sexo y género, resultan particularmente afectadas cuando son reclutadas o alistadas en las filas de las fuerzas armadas o de un grupo armado organizado. Está acreditado que las niñas, sufren un impacto diferenciado al convertirse también en víctimas de violencia sexual como parte de su reclutamiento, a manos de sus superiores o de otros miembros del grupo. Nuevamente, la jurisprudencia de la Corte Penal Internacional, esta vez para el caso de Bosco Ntaganda, ha buscado reaccionar frente a dicha situación, llenando los vacíos de una protección que se extraña en el DIH y el DIDH. Al ser este un caso que se encuentra en una etapa procesal bastante inicial, nos resta solo mirar expectantes las próximas acciones del Tribunal en La Haya.

\section{Referencias Bibliográficas}

Ambos, Kai. 2011. Defences in International Criminal Law. En Research Handbook on International Criminal Law. Alemania.

2012a. El primer fallo de la Corte Penal Internacional (Prosecutor vs. Lubanga): un análisis integral de las cuestiones jurídicas. INDRET: Revista para el Análisis del Derecho 3.

2012b. Violencia sexual en conflictos armados y Derecho Penal Internacional. Cuadernos de Política Criminal 107 (octubre): 5-50.

American Non-Governmental Organizations Coalition for the International Criminal Court. 2012. Background paper: the veredict in the case of the Prosecutor vs. Thomas Lubanga Dyilo. Nueva York: Columbia University.

Amnistía Internacional. 2013. En el conflicto de Mali hay niños y niñas soldados. http://www.es.amnesty.org/actua/acciones/ mali-ninos-ninas-soldados/

Beah, Ismael. 2007. A long way gone. Memoirs of a boy soldier. New York: Sarah Crichton Books.
Bolaños, Jorge. 2013. Conflicto armado en la República Centroafricana: el desenlace inevitable de un frustrado proceso de Paz. En Documento Informativo del Instituto Español de Estudios Estratégicos.

Bouvier, Antoine, Anne Quintin y Marco Sassòli. 2014. How does law protect in war? $3^{\mathrm{a}}$ ed. Geneva: International Committee of the Red Cross.

Cardoso, Emanuela. 2011. La violencia sexual contra las mujeres en los conflictos armados. Un análisis de la jurisprudencia de los Tribunales ad hoc para la ex - Yugoslavia y Ruanda. INDRET: Revista para el análisis de Derecho 4.

2011. La violencia sexual contra las mujeres en los conflictos armados. Un análisis de la jurisprudencia de los Tribunales ad hoc para la ex - Yugoslavia y Ruanda. INDRET. Revista para el análisis de Derecho 4.

Centro de Noticias de la ONU. República Centroafricana: UNICEF insta a cesar reclutamiento de niños soldados. http:// www.un.org/spanish/News/story. asp?News ID=25358\#.UYIrSbV95qV

UNICEF calcula hasta 300.000 niños soldados en el mundo. http://www.un.org/ spanish/News/story.asp?NewsID=22697\#. UYInYbV95qU

Child Soldiers International. 2012. Louder than words: An agenda for action to end states use of child soldiers. Londres: Oxuniprint.

Comisión de la Verdad y Reconciliación del Perú. Informe Final. 28 de agosto de 2013.

Comité Internacional de la Cruz Roja. 2003. Protección Jurídica de los niños en los conflictos armados. http://www.icrc.org/spa/ assets/files/other/ninos.pdf 
Valeria Reyes Menéndez

2011. El Derecho Internacional Humanitario y los desafíos de los conflictos armados contemporáneos. Ginebra.

Consejo de Seguridad de Naciones Unidas. Resolución No. 1315. Aprobada por el Consejo de Seguridad en su $4186^{a}$ sesión, celebrada el 14 de agosto de 2000.

Corte IDH. Caso Vargas Areco vs. Paraguay. Fondo, Reparaciones y Costas. Sentencia de 26 de septiembre de 2006. Serie C No. 155.

Corte Penal Internacional. 2007. The Prosecutor vs. Thomas Lubanga. Decisión de confirmación de cargos.

2012a. Situación en la República Democrática del Congo en el caso del Fiscal contra Thomas Lubanga Dyilo. Decisión pública sobre la pena de conformidad con el artículo 76 del Estatuto.

2012b. Situación en la República Democrática del Congo en el caso del Fiscal contra Thomas Lubanga Dyilo. Decisión pública sobre la pena de conformidad con el artículo 74 del Estatuto.

2014a. Policy paper on Sexual Gender-Based Crimes. Oficina de la Fiscalía.

https://www.icc-cpi.int/iccdocs/otp/OTP-Policy-Paper-onSexual-and-Gender-Based-Crimes--June-2014.pdf

2014b. Ntaganda, Decision Pursuant to Article 61(7)(a) and (b) of the Rome Statute on the Charges of the Prosecutor Against Bosco Ntaganda. Caso No. ICC-01/04-02/06-309.

2016. Décision relative à la confirmation des charges contre Dominic Ongwen.

2017. The Prosecutor vs. Bosco Ntaganda. Judgment on the appeal of Mr. Ntaganda against the "Second decision on the Defence's challenge to the jurisdiction of the Court in respect of Counts 6 and 9". Caso No. ICC-01/04-02/06-1962.

Dudenhoefer, Anne-Lynn. Understanding the Recruitment of Child Soldiers in Africa. African Center for the Constructive Resolution of Disputes (ACCORD). http://www.accord.org.za/ conflict-trends/understanding-recruitment-child-soldiers-africa/
Fight Slavery Now. Child Soldiers. http:// fightslaverynow.org/why-fight-there-are-27million-reasons/otherformsoftrafficking/childsoldiers/

Grey, Rosemary. 2014. Sexual Violence against Child Soldiers. The limits and potential of International Criminal Law. International Feminist Journal of Politics 4, Vol. 16 (diciembre): 601-21. https://doi.org/10.1080/1 4616742.2014 .955964

Grignon, Julia. 2014. The beginning of application of international humanitarian law: A discussion of a few challenges. International Review of the Red Cross 893, Vol. 96 (marzo): 139-62. https://doi.org/10.1017/ s1816383115000326

Gutierrez, Hortensia. 2006. La relación entre el derecho internacional humanitario y los tribunales penales internacionales. International Review of the Red Cross 861 (marzo).

HCJ 769/02. Supreme Court of Israel. 2005. Public Committee vs. Government of Israel. http://elyon1.court.gov.il/Files ENG/02/690/007/A34/02007690.A34.pdf

Henckaerts, Jean-Marie y Louise Doswaldbeck. 2005. Rules. Vol. I de Customary International Humanitarian Law. Cambridge: Cambridge University Press.

Human Rights Watch. Mali: Islamists should free child soldiers. http://www.hrw.org/ news/2013/01/15/mali-islamists-should-freechild-soldiers

2003. My Gun was as Tall as Me: Child Soldiers in Burma. Democratic Voice of Burma News. http://www.hrw.org/reports/2002/burma/

2004. Aprenderás a no llorar: Niños combatientes en Colombia. 
Los niños y las niñas en la guerra: Respuestas desde el Derecho Internacional frente a los crímenes de reclutamiento de niñas y niños soldados y violencia sexual Children in war: Answers from International Law to the crimes of recruitment of child soldiers and sexual violence

2012. First Veredict at the International Criminal Court: The case of the Prosecutor v. Thomas Lubanga Dyilo: Questions and Answers.

Humphryes, Gary. 2009. Healing child soldiers: a United Nations treaty prohibiting the use of children in hostilities has been ratified by 126 countries, but at least 250000 child soldiers are currently involved in armed conflicts worldwide. The United Nations children's fund (UNICEF) and its partners struggle to repair the damage. Bulletin of the World Health Organization 5, Vol.87 (mayo): 330-31. https://doi:10.2471/ BLT.09.020509

Integrated Regional Information Networks. 2011. Afghanistan: Taliban deny children being used as suicide bombers. http://www. irinnews.org/indepthmain. aspx?indepthid=94\& reportid $=92790$

Kirs, Eszter. 2006. Save the children of War! Thoughts on child recruitment. Acta Societatis Martensis 2: 93-107. http:// publikacio.uni-miskolc.hu/data/ME-PUB-10101/Kirs_save.pdf

Kleffner, Jann. 2007. From 'belligerents' to 'fighters' and civilians Directly participating in hostilities - on the Principle of Distinction in non-international armed Conflicts one hundred years after the second Hague Peace Conference. Netherlands International Law Review 2, Vol.54 (Agosto): 315-336. https:// doi.org/10.1017/S0165070X07003154

Linberg, Marte. 2010. How to make the Interpretive Guidance on the Notion of Direct Participation in Hostilities under International Humanitarian Law practicable to operational forces? Suecia: University of Oslo.

Melzer, Nils. 2010. Guía para interpretar la noción de participación directa en las hostilidades según el derecho internacional humanitario. Ginebra: Comité Internacional de la Cruz Roja.

Milanovic, Marko. 2014. The end of application of international humanitarian law. International Review of the Red Cross 893, Vol. 96 (marzo): 163-88. https://doi.org/10.1017/ s181638311500003x

Miller, Sarah Rose. 2002. Child Soldiers. The Humanist 4, Vol. 62 (julio).
Moreno Martin, Florentino y otros. 2010. ¿Por qué se vinculan las niñas a los grupos guerrilleros y paramilitares en Colombia? Revista Latinoamericana de Psicología 3, Vol. 42: 453-67.

Núñez, Raúl y Lady Zuluaga. 2011. La violencia sexual como una forma de tortura en el Derecho Internacional de los Derechos Humanos. Criterio jurídico 1, Vol.11.

Núñez del Prado, Fabiana. 2012. La construcción del crimen internacional de violación sexual contra la mujer en el desarrollo de la jurisprudencia de los Tribunales Penales Internacionales Ad-Hoc. Tesis de licenciatura, Pontificia Universidad Católica del Perú.

Ortiz, Isabel y Matthew Cummins. 2012. Desigualdad Global: La distribución del ingreso en 141 países. En Documento de Trabajo sobre política económica y social. UNICEF.

Pardo Segovia, Fernando. 2001. La Corte Penal Internacional y su competencia ratione personae, ratione loci y ratione temporis. En $\mathrm{La}$ Corte Penal Internacional y las medidas para su implementación en el Perú, coord. Elizabeth Salmón. Lima: Fondo Editorial de la PUCP.

Reyes Milk, Michelle. 2008. El principio de inmunidad de los Jefes de Estado en actividad frente a la comisión de crímenes internacionales. Agenda Internacional 26: 69-106.

Rodenhäuser, Tilman. 2016. Squaring the Circle? Prosecuting Sexual Violence against Child Soldiers by their "Own Forces". Journal of International Criminal Justice 14 (marzo): 171-93. https://doi.org/10.1093/jicj/mqw006

Rodríguez Villasante, José Luis. 2011. La protección del niño en los conflictos armados por el derecho internacional humanitario. 


\section{Valeria Reyes Menéndez}

Los niños soldados. Anuario de la Facultad de Derecho de la Universidad Autónoma de Madrid 15: 217-39.

Salmón, Elizabeth. 2006. Los aportes del Derecho Internacional de los Derechos Humanos a la protección del ser humano. En Miradas que construyen. Perspectivas multidisciplinarias sobre los derechos humanos. Lima: Fondo Editorial de la Pontificia Universidad Católica del Perú.

2014. Introducción al Derecho Internacional Humanitario. Perú: Pontificia Universidad Católica del Perú, Instituto de Democracia y Derechos Humanos y Comité Internacional de la Cruz Roja.

Salmón, Elizabeth y Cristina Blanco. 2012. El derecho al debido proceso en la jurisprudencia de la Corte Interamericana de Derechos Humanos. Lima: Instituto de Democracia y Derechos Humanos de la Pontificia Universidad Católica del Perú (IDEHPUCP) y Cooperación Alemana al Desarrollo (GIZ).

Sandoz, Yves, Cristophe Swinarski y Bruno Zimmerman ed. 1987. Comentarios al Protocolo Adicional I del 08 de junio de 1977 a los Convenios de Ginebra de 1949. Ginebra: Comité Internacional de la Cruz Roja.

Save The Children, Coordinadora Nacional de Derechos Humanos. 2010. Niños Soldados: Informe presentado a la Comisión Interamericana de Derechos Humanos en su $138^{\circ}$ periodo de sesiones.

Secretario General de las Naciones Unidas. 2017. Los niños y los conflictos armados. Informe del Secretario General A/72/361-S/2017/821.

Singer, Peter Warren. 2001. Caution: Children at war. Parameters Vol.40 (invierno).
SOS, Children's Villages. Child Soldiers in DRC. http://www. child-soldier.org/child-soldiers-in-drc

Tribunal Especial para Sierra Leona. Prosecutor vs. Charles Ghankay Taylor. Sentencia. 30 de mayo de 2012.

Prosecutor vs. Moinina Fofana and Allieu Kondewa. Sentencia de primera instancia. 2 de agosto de 2007.

Prosecutor vs. Brima, Kamara and Kanu. Sentencia. 20 de junio de 2007.

Prosecutor vs. Charles Ghankay Taylor. Sentencia. 18 de mayo de 2012.

Prosecutor vs. Issa Hassan Sessay, Morris Kallon, Augustine Gbao. Sentencia. 8 de abril de 2009.

Tribunal Penal Internacional para la Ex - Yugoslavia. Prosecutor vs. Anto Furundzija. Fallo. 10 de diciembre de 1998.

Tribunal Penal Internacional para Ruanda. Prosecutor vs. Jean Paul Akayesu. Fallo. 2 de setiembre de 1998.

Trueman, Chris. Hitler Youth Movement. http://www. historylearningsite.co.uk/nazi-germany/hitler-youthmovement/

UNICEF. 2012. Child Soldiers. UNICEF News. http://www. unicef.org.au/Discover/News/March-2012/Child-Soldiers. aspx\#

War Child. http://www.warchild.org.uk/issues/child-soldiers

Watch List on Children and armed conflict. 2012. Nadie en quien confiar. Los niños y el conflicto armado en Colombia. http:// watchlist.org/wp-content/uploads/Watchlist-ColombiaReportSpanish-LR.pdf

Yuvaraj, Joshua. 2016. When Does a Child 'Participate Actively in Hostilities' under the Rome Statute? Protecting Children from Use in Hostilities after Lubanga. Utrecht Journal of International and European Law 83, Vol. 32 (Septiembre): 69-93. doi:10.5334/ujiel.321. 